\title{
Causes and predictors of hospitalization and in-hospital mortality among HIV/AIDS patients on highly active antiretroviral therapy in secondary and tertiary care hospitals in Oromia Regional State: multi-center cross-sectional study
}

\author{
Gurmu T. Umeta ${ }^{1}$, Legese Chelkeba ${ }^{2}$, Gosaye M. Tefera ${ }^{1}$, Kemal Jemal ${ }^{3}$, Kabaye K. Goro ${ }^{2}$ \\ ${ }^{1}$ Department of Pharmacy, Clinical Pharmacy Course Unit, Ambo University, Ambo, Ethiopia \\ ${ }^{2}$ Department of Clinical Pharmacy, School of Pharmacy, Institute of Health Sciences, Jimma University, Jimma, Ethiopia \\ ${ }^{3}$ Department of Nursing, College of Health Sciences, Salale University, Fitche, Ethiopia
}

\begin{abstract}
Introduction: Highly active antiretroviral therapies (HAART) decrease the incidence, morbidity, and mortality of acquired immunodeficiency syndrome (AIDS) dramatically. However, current research reported an increased hospitalization rate among AIDS patients. Therefore, this study aimed to determine causes and predictors of hospital admission as well as in-hospital mortality amongst human immunodeficiency virus (HIV)/AIDS-infected patients on HAART.

Material and methods: This was a multi-center cross-sectional study, and included HIV/AIDS patients who were admitted to secondary and tertiary care hospitals in Oromia Regional State from May 1, 2017, to August 30, 2017. Data were collected from hospitalized HIV/AIDS patients using structured checklist and interview. Results were analyzed with Statistical Package for Social Sciences (SPSS) software, version 22. Bivariate and multivariable logistic regression analysis were performed to evaluate association, and $p$-value $<0.05$ was used to determine relationship between dependent and independent variables.

Results: Out of 171 participants enrolled, 105 (61\%) were hospitalized due to opportunistic infections. Age ranged from 40 to 49 ( $\mathrm{AOR}=0.30 ; 95 \% \mathrm{CI}$ : $0.09-0.98 \%)$ vs. $18-29$, females $(\mathrm{AOR}=2.41$; 95\% CI: 1.11-5.24\%), CD4+ count less than 200 (AOR = 10.32; 95\% CI: 3.49-30.52\%), and poor adhered $(\mathrm{AOR}=2.78$; 95\% CI: 1.21-6.41\%) were significantly related to hospitalization with opportunistic infections (AIDS-related illnesses). Among admitted patients, 20 (11.7\%) died in hospital. Poorly adherent patients and those who spent 9 days or more in hospital were more exposed to in-hospital death, with $\mathrm{AOR}=3.093$; 95\% CI: $1.012-9.453 \%$ and $\mathrm{AOR}=4.533$; 95\% CI: $1.371-14.985 \%$, respectively.

Conclusions: The major causes of hospitalization were HIV/AIDS-related illnesses. Adherence to the HIV drug regimen is warranted to minimize hospitalization with opportunistic infections and HIV/AIDS mortality.
\end{abstract}

HIV AIDS Rev 2021; 20, 2: 102-108

DOI: https://doi.org/10.5114/hivar.2021.107236

Key words: highly active antiretroviral therapy, hospital admission, human immune virus (HIV).

Address for correspondence: Prof. Gurmu Tesfaye Umeta, Department of Pharmacy, Clinical Pharmacy Course Unit, Ambo University, Ambo, Ethiopia, e-mail: gurmut6@gmail.com
Article history:

Received: 09.08.2020

Received in revised form: 29.09.2020

Accepted: 30.09.2020

Available online: 30.06 .2021
International Journal of HIV-Related Problems

HIV \& AIDS

R e vi e w 


\section{Introduction}

Human immunodeficiency virus (HIV) and acquired immunodeficiency syndrome (AIDS) are a foremost public health difficulty with the worldwide new cases of 2.1 million and 1.1 million deaths, out of which about $42.7 \%$ was in Eastern and South African region [1]. Highly active antiretroviral therapy (HAART), a combination of three and more HIV repressing drugs, has appreciably enhanced the immunological standing of infected people, making HIV a controllable illness [2]. Thriving antiretroviral treatment contains viral reproduction [3]. CD4+ T cell lymphocyte count is one of the main significant predictive factors for worsening of HIV infection, and the root for suggestion in the initiation of antiretroviral management and prophylaxis [4].

HAART could decrease the incidence [5], morbidity [5, 6], and mortality [5-7] of AIDS dramatically. However, current studies reported an increased rate of hospitalization among AIDS patients, which was up to $26.6 \%$ [8] regardless of remarkable worldwide increase of HAART treatment [1]. Furthermore, the rate and length of hospitalization was higher in these patients than wide-ranging population [9].

This in turn was accompanied with a bigger danger of death larger than about $20 \%$, as revealed in studies from Brazil, Iran, and Uganda, showing death rate of $44.8 \%$, $25.7 \%$, and $21 \%$ among hospitalized AIDS patients, respectively [10-12].

Limited studies were performed evaluating causes of hospitalization and in-hospital mortality among general cohorts of AIDS patients during HAART. Moreover, these studies had various limitations. First, almost all of them were retrospective in nature using card review or secondary data collection, which might elevate a problem of incompleteness, such as clinical characteristics and a few of laboratory investigations (e.g., CD4+ count level) missing [13-15]. The second limitation included lack of representativeness, as majority of them were done in a single university or teaching hospital, which might not represent the whole picture of health setting [12-14, 16]. The third and final limitation was they had no uniformity in reporting the cause for hospitalization and in-hospital mortality. Some reported an increased risk of mortality with AIDS-related illness in the recent era of HAART, due to late presentation and being HAART naïve $[6,8]$. On the contrary, others found non-AIDS-related illness, like cardiovascular, malignancy, non-AIDS-related infections, and drug toxicity as the major causes of mortality in this group of patients $[17,18]$.

In order to fill-up the above-mentioned gaps with previously published works, the present multi-center cross-sectional study aimed to determine causes of hospital admission, predictors of admission with opportunistic infection, and in-hospital mortality among HIV/AIDS-infected individuals on HAART in secondary and tertiary hospitals in Oromia Regional State.

\section{Material and methods}

\section{Study setting, time, and design}

A hospital-based cross-sectional study design was employed from May 1, 2017, to August 30, 2017, in Oromia Regional State, Ethiopia. In Oromia, there are nearly 36 hospitals (32 general hospitals and 4 referral hospitals), out of which 12 hospitals were selected using a lottery method. In total, 10 hospitals were included in the present study, 2 excluded because of unwillingness (i.e., Fiche Hospital, Shashamene Hospital). $1 / 3^{\text {rd }}$ of the hospitals were chosen to ensure representativeness of the data. The names of hospitals included Nekemte Referral Hospital, Ambo General Hospital, Bishoftu General Hospital, Adama Hospital Medical College, Jimma University Medical Center, St. Lukas Hospital, Mettukarl Hospital, Chiro Hospital, Goba General Hospital, and Assella Hospital. These hospitals provide a wide range of services, such as voluntary counseling and testing (VCT), prevention of mother-to-child transmission, antiretroviral therapy, treatment of opportunistic infections, and other curative services. Medical wards were considered and patients admitted there were included in the present study, since HIV/AIDS patients are mainly managed in these departments.

\section{Study population}

All HIV/AIDS patients on HAART who were admitted to a medical ward at a period of data acquisition were involved in the present study. Those patients who were on HAART for less than 6 months and were re-admitted after first discharge with an improvement were excluded.

\section{Sampling amount and sampling procedures}

General and referral hospitals in Oromia Regional State were considered as the study hospitals and were chosen using a lottery method. Therefore, all the consecutive participants who fulfilled the inclusion criteria were enrolled into 4 months study. Pre-tested and standardized questionnaire were adapted from different literature and modified to fit the local context [14-22]. Data were collected by ten nurses, with two clinical pharmacists as supervisors. The questionnaires contained independent variables, such as demography (age, gender, body mass index (BMI), employment status), CD4+ count, adherence level, prophylaxis (cotrimoxazole prevention therapy [CPT], isoniazid prevention therapy [IPT]), and length of hospitalization. Adherence was measured using patient self-report, and dependent variables included cause of hospital admission and in-hospital mortality.

Causes of hospitalization were categorized based on diagnoses of disease conditions that lead to a hospitalization. If a patient had multiple diagnoses during hospitalization, one underlying cause of hospitalization would be determined by applying the following priority order: (1) WHO stage 4 
Table 1. Socio-demographic and clinical characteristics of the study participants from Oromia Regional State hospitals, Ethiopia

\begin{tabular}{|c|c|}
\hline Factor & $n(\%)$ \\
\hline \multicolumn{2}{|l|}{ Age, years } \\
\hline $18-29$ & $42(26.6)$ \\
\hline $30-39$ & $61(35.7)$ \\
\hline $40-49$ & $40(23.4)$ \\
\hline$\geq 50$ & $28(16.3)$ \\
\hline \multicolumn{2}{|l|}{ Sex } \\
\hline Male & $74(43.3)$ \\
\hline Female & $97(56.7)$ \\
\hline \multicolumn{2}{|l|}{ Employment status } \\
\hline Employed & $123(71.9)$ \\
\hline Not employed & $48(28.1)$ \\
\hline \multicolumn{2}{|l|}{ Body mass index } \\
\hline Malnutrition & $60(35.1)$ \\
\hline Normal range & $103(60.2)$ \\
\hline Overweight & $8(4.7)$ \\
\hline \multicolumn{2}{|l|}{ Current CD4+ count level } \\
\hline Greater than 200 & $52(30.4)$ \\
\hline Less than 200 & $119(69.6)$ \\
\hline \multicolumn{2}{|c|}{ Isoniazid prevention therapy } \\
\hline Yes & $102(59.6)$ \\
\hline No & $69(40.4)$ \\
\hline \multicolumn{2}{|c|}{ Cotrimoxazole prevention therapy } \\
\hline Yes & $155(90.6)$ \\
\hline No & $16(9.4)$ \\
\hline \multicolumn{2}{|l|}{ Time on HAART } \\
\hline Less than 5 years & 99 (57.9) \\
\hline Greater than 5 years & $72(42.1)$ \\
\hline \multicolumn{2}{|l|}{ Adherence level } \\
\hline Good & $64(62.6)$ \\
\hline Poor & $107(37.4)$ \\
\hline
\end{tabular}

opportunistic disease; (2) WHO stage 3 opportunistic disease; (3) other infection; (4) other cancer; (5) other disease. Finally, the underlying causes of hospitalization were grouped into two broad categories, such as HIV/AIDS and non-HIV/ AIDS reason of admission.

\section{Data handling and investigation}

Firstly, data was applied into Epi-data version 4.4 and transferred to Statistical Package for Social Sciences software, version 22.0 , for data analysis. The descriptive data analysis was performed and presented as frequency, summary statistics, and table. Bivariate and multiple variable logistic regressions were done to identify associated factors. Both crude and adjusted odds ratios with $95 \%$ confidence interval were computed, and statistical importance was confirmed at $p$-value $<0.05$.

\section{Consideration of ethics}

Research ethical clearance letter was initially attained from the Jimma University Institute of Health Science Researches' ethical board, No. IHRPGC/348/2017. Then, the ethical clearance together with a support letter from the Jimma University was given to ethical review committee of Oromia Regional Health Bureau (ORHB) for a revision. The final support letter written to respective hospitals was obtained from ORHB. Then, a written consent was secured from chief executive officer (CEO) of the selected hospitals and provided to a ward senior or responsible person to get a permission. Finally, data collectors informed the patients about the study's main objectives and any unclear point related to the study, after which, an informed consent was taken from each individual. To ensure confidentiality of respondents, their names were excluded from the questionnaire.

\section{Results}

From 12 hospitals selected to be included in this study, only 10 hospitals had shown their willingness to contribute. A total of 171 participants were enrolled for over 4 months period from 10 hospitals. The age of study participants ranged from 18 to 70 years. The mean age of the participants was $36.66 \pm 11.8$. The higher proportion, 61 (35.7\%) were in the age range of 30 to 39 years, and the majority, 97 (56.7\%) of enrolled were females. About 123 (71.9\%) of the individuals were employed. The majority of the participants, 103 (60.2\%), had normal body mass index, and greater than twothird of the patients had greater than 200 CD4+ count. Ninetenth and three-fifth of the study participants were taken prophylaxes of cotrimoxazole and isoniazid prevention therapy to prevent opportunistic infections, respectively. Greater than half, 99 (57.9\%) of the study participants were less than five years' time on HAART. The majority, 107 (62.6) of them had a good adherent to their HAART medication (Table 1).

\section{Causes for hospital admission among the study participants}

105 (61\%) out of 171 participants hospitalization was caused by AIDS-related illness, while 66 patients (39\%) were admitted as a result of non-AIDS-related illnesses.

\section{Predictors of hospital admission with opportunistic infection among the study participants}

In the bivariate analysis, variables, such as the age category of 40 to 49 years, males, current CD4+ count less than 200, less than 5 years on HAART, and poor adherence level 
Table 2. Bivariate and multivariate logistic regression to determine predictors of causes of hospital admission among HIV/ AIDS patients on highly active antiretroviral therapies (HAART)

\begin{tabular}{|c|c|c|c|c|c|c|}
\hline \multirow[t]{2}{*}{ Variables } & \multicolumn{2}{|c|}{$\begin{array}{l}\text { Admission with AIDS- } \\
\text { related illness }\end{array}$} & \multirow[t]{2}{*}{ COR $(95 \% \mathrm{Cl})$} & \multirow[t]{2}{*}{$p$-value } & \multirow[t]{2}{*}{ AOR $(95 \% \mathrm{Cl})$} & \multirow[t]{2}{*}{$p$-value } \\
\hline & Yes & No & & & & \\
\hline \multicolumn{7}{|l|}{ Age in completed years } \\
\hline $18-29$ & 12 & 30 & 1.00 & & 1.00 & \\
\hline $30-39$ & 26 & 35 & $0.54(0.23-1.25)$ & 0.149 & $0.81(0.27-2.41)$ & 0.707 \\
\hline $40-49$ & 19 & 21 & $0.44(0.18-1.10)$ & 0.080 & $0.30(0.09-0.98)$ & 0.046 \\
\hline$\geq 50$ & 9 & 19 & $0.84(0.30-2.38)$ & 0.750 & $0.93(0.24-3.55)$ & 0.911 \\
\hline \multicolumn{7}{|l|}{ Sex } \\
\hline Male & 22 & 52 & $1.96(1.04-3.72)$ & \multirow{2}{*}{0.039} & $2.41(1.11-5.24)$ & \multirow{2}{*}{0.026} \\
\hline Female & 44 & 53 & 1.00 & & 1.00 & \\
\hline \multicolumn{7}{|l|}{ Employment status } \\
\hline Yes & 50 & 73 & 1.00 & \multirow{2}{*}{0.378} & 1.00 & \multirow{2}{*}{0.463} \\
\hline No & 16 & 32 & $1.37(0.68-2.76)$ & & $1.45(0.54-5.87)$ & \\
\hline \multicolumn{7}{|l|}{ Nutrition status } \\
\hline Malnutrition & 22 & 46 & $1.56(0.82-2.96)$ & \multirow{2}{*}{0.174} & $1.16(0.53-2.54)$ & \multirow{2}{*}{0.710} \\
\hline Normal & 44 & 59 & 1.00 & & 1.00 & \\
\hline \multicolumn{7}{|l|}{ Current CD } \\
\hline Greater than 200 & 5 & 47 & 9.89 (3.68-26.59) & \multirow{2}{*}{0.000} & $10.32(3.49-30.52)$ & \multirow{2}{*}{0.000} \\
\hline Less than 200 & 61 & 58 & 1.00 & & 1.00 & \\
\hline \multicolumn{7}{|c|}{ Isoniazid prevention therapy } \\
\hline No & 25 & 44 & $1.18(0.63-2.22)$ & \multirow{2}{*}{0.602} & $1.19(0.52-2.71)$ & \multirow{2}{*}{0.681} \\
\hline Yes & 41 & 61 & 1.00 & & 1.00 & \\
\hline \multicolumn{7}{|c|}{ Cotrimoxazole prevention therapy } \\
\hline No & 6 & 10 & $1.05(0.36-3.05)$ & \multirow{2}{*}{0.925} & $1.24(0.32-4.88)$ & \multirow{2}{*}{0.758} \\
\hline Yes & 60 & 95 & 1.00 & & 1.00 & \\
\hline \multicolumn{7}{|l|}{ Time on HAART } \\
\hline Less than 5 years & 31 & 68 & $2.08(1.11-3.89)$ & \multirow{2}{*}{0.023} & $1.73(0.80-3.71)$ & \multirow{2}{*}{0.161} \\
\hline Greater than 5 years & 35 & 37 & 1.00 & & 1.00 & \\
\hline \multicolumn{7}{|l|}{ Adherence level } \\
\hline Good & 15 & 49 & $2.98(1.49-5.94)$ & \multirow{2}{*}{0.002} & $2.78(1.21-6.41)$ & 001 \\
\hline Poor & 51 & 56 & 1.00 & & 1.00 & 0.010 \\
\hline
\end{tabular}

were the factors significantly associated with admission of patients with AIDS-related illnesses (opportunistic infections), and time on HAART for less than 5 years was adjusted in multiple variables.

In multiple variables logistic regression analysis, the odds with the age range of 40 to 49 years were about $30 \%$ more likely admitted with AIDS-related illness than the age range between 18 to 29 years (AOR $=0.30$; 95\% CI: 0.09-0.98\%). Females were twice more likely to be admitted with AIDS-related illness compared to males (AOR $=2.41 ; 95 \% \mathrm{CI}: 1.11-5.24 \%$ ). The likelihood of current CD4+ count less than 200 was ten times more likely predictor of admission with AIDS-related illness compared to those with CD4+ count greater than 200
Table 3. Incidence of death among admitted HIV/AIDS patients on highly active antiretroviral therapies in Oromia Regional State, Ethiopia, 2017

\begin{tabular}{l|c}
\hline In-hospital death & $n(\%)$ \\
\hline No & $151(88.3)$ \\
\hline Yes & $20(11.7)$ \\
\hline Total & $171(100)$ \\
\hline
\end{tabular}

$(\mathrm{AOR}=10.32 ; 95 \% \mathrm{CI}: 3.49-30.52 \%)$. Those poorly adhered to their treatment regimen were three times more likely to be admitted as a result of AIDS-related illness than those with good adherent $(\mathrm{AOR}=2.78$; 95\% CI: 1.21-6.41\%) (Table 2). 
Table 4. Bivariate and multivariate logistic regression to determine predictors of causes of hospital admission among HIV/ AIDS patients on highly active antiretroviral therapies (HAART)

\begin{tabular}{|c|c|c|c|c|c|c|}
\hline \multirow{2}{*}{ Variables } & \multicolumn{2}{|c|}{ In-hospital mortality } & \multirow{2}{*}{$\operatorname{COR}(95 \% \mathrm{Cl})$} & \multirow{2}{*}{$p$-value } & \multirow{2}{*}{ AOR $(95 \% \mathrm{Cl})$} & \multirow{2}{*}{$p$-value } \\
\hline & No & Yes & & & & \\
\hline \multicolumn{7}{|l|}{ Reason for admission } \\
\hline $\begin{array}{l}\text { AIDS } \\
\text { (opportunistic infection) }\end{array}$ & 61 & 5 & 1.00 & 0.747 & & \multirow[t]{2}{*}{0.678} \\
\hline Non-AIDS-related & 90 & 15 & $0.983(0.221-4.377)$ & 0.982 & $0.747(0.188-2.960)$ & \\
\hline \multicolumn{7}{|l|}{ Age in completed years } \\
\hline $18-29$ & 34 & 8 & 1.00 & 0.099 & 1.00 & 0.134 \\
\hline $30-39$ & 61 & 0 & 0.00 & 0.00 & 0.00 & 0.997 \\
\hline $40-49$ & 36 & 4 & $0.229(0.037-1.431)$ & 0.115 & $0.399(0.100-1.589)$ & 0.193 \\
\hline$\geq 50$ & 20 & 28 & $1.938(0.429-8.756)$ & 0.390 & $2.398(0.668-8.616)$ & 0.180 \\
\hline \multicolumn{7}{|l|}{ Sex } \\
\hline Males & 63 & 11 & 1.00 & \multirow{2}{*}{0.336} & 1.00 & \multirow{2}{*}{0.241} \\
\hline Females & 88 & 9 & $0.554(0.166-1.845)$ & & $0.504(0.160-1.586)$ & \\
\hline \multicolumn{7}{|l|}{ Unemployment status } \\
\hline Yes & 41 & 7 & 1.00 & \multirow{2}{*}{0.755} & & \multirow{2}{*}{0.703} \\
\hline No & 110 & 13 & $1.275(0.277-5.871)$ & & $1.333(0.304-5.846)$ & \\
\hline \multicolumn{7}{|l|}{ Nutrition status } \\
\hline Normal & 95 & 8 & 1.00 & \multirow{2}{*}{0.034} & 1.00 & \multirow{2}{*}{0.057} \\
\hline Malnutrition & 56 & 12 & $3.735(1.103-12.647)$ & & $2.961(0.969-9.045)$ & \\
\hline \multicolumn{7}{|l|}{ Current CD4+ count } \\
\hline Greater than 200 & 45 & 7 & 1.00 & \multirow{2}{*}{0.300} & & \multirow{2}{*}{0.200} \\
\hline Less than 200 & 106 & 13 & $1.981(0.544-7.210)$ & & $2.219(0.655-6.186)$ & \\
\hline \multicolumn{7}{|l|}{$\begin{array}{l}\text { Isoniazid prevention } \\
\text { therapy }\end{array}$} \\
\hline Yes & 91 & 11 & 1.00 & \multirow{2}{*}{0.172} & & \multirow{2}{*}{0.223} \\
\hline No & 60 & 9 & $2.433(0.679-8.720)$ & & $2.011(0.654-6.186)$ & \\
\hline \multicolumn{7}{|l|}{$\begin{array}{l}\text { Cotrimoxazole prevention } \\
\text { therapy }\end{array}$} \\
\hline Yes & 137 & 18 & 1.00 & \multirow{2}{*}{0.869} & & \multirow{2}{*}{0.828} \\
\hline No & 14 & 2 & $0.829(0.090-7.621)$ & & $0.787(0.091-6.811)$ & \\
\hline Time on HAART & & & & & & \\
\hline Less than 5 years & 89 & 10 & 1.00 & 0743 & 1.00 & 0728 \\
\hline Greater than 5 years & 62 & 10 & $1.218(0.375-3.956)$ & 0.143 & $1.226(0.388-3.880)$ & $0.1<0$ \\
\hline Adherence level & & & & & & \\
\hline Good & 53 & 11 & 1.00 & 0 & 1.00 & \\
\hline Poor & 98 & 9 & $3.832(1.007-14.588)$ & 0.049 & $3.093(1.012-9.453)$ & 0.040 \\
\hline Length of hospitalization & & & & & & \\
\hline$<9$ days & 85 & 5 & 1.00 & 0.021 & 1.00 & 0013 \\
\hline$\geq 9$ days & 66 & 15 & $4.918(1.266-19.110)$ & 0.021 & $4.533(1.371-14.985)$ & 0.013 \\
\hline
\end{tabular}

\section{Incidence of death among the study participants}

The incidence of death in this study was $11.7 \%$ (20 cases), and $88.3 \%$ (151 cases) of patients were discharged.

\section{Mortality and its associates}

As presented in the following table using bivariate analysis, nutrition status, level of adherence, and length of hospital stay have shown a significant association with hospital 
mortality at $p$-value of $0.034,0.049$, and 0.21 , respectively. Upon backward stepwise logistic regression, poor adherence and prolonged hospital stay (i.e., greater than 9 days) were found to have a significant association with in-hospital mortality. Accordingly, those individuals who were poorly adherent to their medications were 3 times more likely to die in hospital than those with good adherence $(\mathrm{AOR}=3.093$; $95 \%$ CI: $1.012-9.453 \%)$. Similarly, the patients who spent 9 days and more in hospital were 4.5 times more likely to die in hospital than those who spent less than 9 days $(\mathrm{AOR}=4.533$; 95\% CI: 1.371-14.985\%) (Table 4).

\section{Discussion}

This present study was carried out in Oromia Regional State hospitals to assess predictors for hospitalization with opportunistic infection among HIV-infected patients receiving HAART. We found that three-fifth of the study participants were hospitalized with AIDS-related illnesses. This result was similar to a study from India [19], which indicated a low adherence to treatment among the study participants. It is obvious that non-adherence increases the risk of hospitalization. Most of the studies show that the most common causes of hospitalization were opportunistic infections $[19,20]$. Similarly in our study, majority of the study participants were hospitalized with opportunistic infections. However, this result was greater than that reported in studies from Iran and Uganda $[12,20]$. On the other hand, our study result was lower than a research conducted in Thailand [13].

In this study, the patients in age category from 40 to 49 years were significantly associated with opportunistic infections as a cause of hospitalization. This might be due to a decrease in immunity as age increases $[21,22]$.

Our study revealed that females were significantly associated with opportunistic infections' hospitalization. Comparably, a study performed in the USA showed females having $51 \%$ of higher rates than males [8]. This is probably because of variation of treatment adherence between the two sexes, which would later result in a difference in the cause of hospitalization [23].

Here, we found that lower CD4+ count was significantly associated with opportunistic infection as a cause of hospitalization. This was similar to a study conducted in Australia, which observed that higher CD4+ cell count was significantly associated with a decreased risk of hospitalization [9]. Deaths are more common in population with CD4+ count less than $200 / \mu \mathrm{L}$ at the time of admission. As the level of CD4+ count increases, the patient recovers from HIV-related illness and the immunity of individual increases [14].

In our study, poor adherence was associated with opportunistic infection as the cause of hospitalization. Poor adherence is a known factor that contributes to HIV/ AIDS-related infections. Most of the patients were uneducated, with little knowledge about medication adherence, and saturated information about their treatment and continuous follow-up during HAART $[24,25]$. Due to discontinuation of their treatment, they are at high-risk for HIV-related illness hos- pitalization. Common challenge in many health systems in Ethiopia is termination of treatments' regimens by patients themselves, which leads to poor treatment outcomes and hospitalization [26].

This study investigated the incidence of in-hospital mortality among HIV-infected patients receiving HAART in hospitals of Oromia Regional State. The incidence of death reported with in current study was lower than that stated in studies done in Brazil, Uganda, and West Africa [11, 12, 27]. This might be because of advancement in treatment and counseling of patients with trends of time, as there was a difference in time among the studies. However, it was greater than studies from Thailand and Barbados [13,28]. These differences were related to study's different setting, period, populations, and design. Poor adherence and prolonged hospital stay have significant association with in-hospital mortality. Both of them were known to contribute to different kinds of infections, apart from prolonged hospital stay that, in particular, would cause hospital's acquired infections, and ultimately would result in hospital death [29].

This study had limitation in a resource constraint of laboratory investigation. Even if there were other laboratory parameters, which could affect the outcome, the study could not show them, as laboratory tests were not done for the majority of patients due to financial difficulties of the participants.

\section{Conclusions}

This study had revealed that HIV/ AIDS-related illnesses are the major causes for hospitalization among patients on HAART. Moreover, poor adherence, low CD4+ count, male sex, and age range from 40 to 49 years were related with opportunist infections (AIDS-related illnesses) as the causes of hospitalization. This research highlights that an appropriate treatment, prevention, and continuous monitoring of HIV/AIDS illness are needed to decrease hospitalization rate due to opportunistic infections. Working to improve adherence to HAART, to prevent AIDS hospitalization, and minimize the risk of opportunistic infections is strongly recommended.

\section{Funding}

This study was financially supported by Jimma University as a postgraduate research study.

\section{Acknowledgment}

We would like to extend our appreciation and thanks to our data collectors, Jimma University Medical Center, and nursing and medical wards' staffs of participated hospitals for their cooperation in various directions, because without their participation, this study had had not been possible to conduct. 


\section{Conflict of interest}

The authors have no conflict of interest.

\section{References}

1. Global AidsUpdate UNAIDS | 2016. [Internet]. Available from: https://www.unaids.org/sites/default/files/media_asset/global-AIDS -update-2016_en.pdf (Accessed: 20.06.2017).

2. Míguez MJ, Rosenberg R, Burbano X, Malow R. Cholesterol as a mediator of alcohol-induced risks for respiratory disease hospitalizations among people living with HIV. J AIDS Clin Res 2011; Suppl 1: 001.

3. Tan D, Yong Y, Tan H, French M, Kamarulzaman A, Price P. Characteristics of natural killer cells in Malaysian HIV patients presenting with immune restoration disease after ART. J AIDS Clinic Res 2010; 1: 102.

4. Achhra AC, Zhou J, Dabis F, et al. Difference in absolute CD4+ count according to CD4 percentage between Asian and Caucasian HIV-infected patients. J AIDS Clin Res 2010; 1: 1-4.

5. Stoneburner R, Korenromp E, Lazenby M, et al. Using health surveillance systems data to assess the impact of AIDS and antiretroviral treatment on adult morbidity and mortality in Botswana. PLoS One 2014; 9: e100431.

6. Catumbela E, Freitas A, Lopes F, et al. HIV disease burden, cost, and length of stay in Portuguese hospitals from 2000 to 2010: a cross-sectional study. BMC Health Serv Res 2015; 15: 144.

7. Báez-Saldaña R, Villafuerte-García A, Cruz-Hervert P, et al. Association between highly active antiretroviral therapy and type of infectious respiratory disease and all-cause in-hospital mortality in patients with HIV/AIDS: a case series. PLoS One 2015; 10 : e0138115.

8. Bachhuber MA, Southern WN. Hospitalization rates of people living with HIV in the United States, 2009. Public Health Rep 2014; 129: $178-186$.

9. Falster K, Wand H, Donovan B, et al. Hospitalizations in a cohort of HIV patients in Australia, 1999-2007. AIDS 2010; 24 : 1329.

10. Hajiabdolbaghi M, Jafari S, Mansouri S, Yaghoobi MH. Hospitalizations and its related factors in HIV/AIDS patients in Tehran, Iran. Med J Islam Repub Iran 2014; 28: 70.

11. Coelho LE, Ribeiro SR, Veloso VG, Grinsztejn B, Luz PM. Hospitalization rates, length of stay and in-hospital mortality in a cohort of HIV infected patients from Rio de Janeiro, Brazil. Braz J Infect Dis 2017; 21: 190-195.

12. Namutebi A, Kamya M, Byakika-Kibwika P. Causes and outcome of hospitalization among HIV-infected adults receiving antiretroviral therapy in Mulago hospital, Uganda. Afr Health Sci 2013; 13 977-985.

13. Liwlompaisan W, Kiertiburanakul S. Causes of hospitalizations among HIV-infected adults in the highly active antiretroviral therapy era in Thailand. J Infect Dis Antimicrob Agents 2013; 30: 5-14.

14. Kumar A, Kilaru KR, Sandiford S, Forde S. Trends in the HIV related hospital admissions in the HAART era in Barbados, 2004-2006. AIDS Res Ther 2007; 4: 4.

15. Lartey M, Asante-Quashie A, Essel A, Kenu E, Ganu V, Neequaye A. Causes of death in hospitalized HIV patients in the early anti-retroviral therapy era. Ghana Med J 2015; 49: 7-11.

16. Guerro AC, Andretta IB, Bello SL, Trevisol DJ, Schuelter-Trevisol F. Causes of hospital admission of AIDS patients in southern Brazil, 2007 to 2012. Rev Soc Bras Med Trop 2014; 47: 632-636.

17. Bane A, Yohannes A, Fekade D. Morbidity and mortality of adult patients with HIV/AIDS at Tikur Anbessa Teaching Hospital, Addis Ababa, Ethiopia. Ethiop Med J 2003; 41: 131-140.

18. Dávalos DM, Hlaing WM, Kim S. Recent trends in hospital utilization and mortality for HIV infection: 2000-2005. J Natl Med Assoc 2010; 102: 1131-1138.
19. Sobhani R, Basavaraj A, Gupta A, et al. Mortality and clinical characteristics of hospitalized adult patients with HIV in Pune, India. Indian J Med Res 2007; 126: 116-121.

20. Sharifi-Mood B, Alavi-Naini R, Salehi M, Hashemi M, Rakhshani F. Spectrum of clinical disease in a series of hospitalized HIV-infected patients from southeast of Iran. Saudi Med J 2006; 27: 1362.

21. Abgrall JM. Healing or Stealing? Medical Charlatans in the New Age. Algora Publishing, 2007.

22. Pabst H, Crawford J. L-tetramisole. Enhancement of human lymphocyte response to antigen. Clin Exp Immunol 1975; 21: 468.

23. Charurat M, Oyegunle M, Benjamin R, et al. Patient retention and adherence to antiretrovirals in a large antiretroviral therapy program in Nigeria: a longitudinal analysis for risk factors. PLoS One 2010; 5: e10584.

24. Llabre MM, Weaver KE, Durán RE, Antoni MH, McPherson-Baker S, Schneiderman N. A measurement model of medication adherence to highly active antiretroviral therapy and its relation to viral load in HIV-positive adults. AIDS Patient Care STDS 2006; 20: 701-711.

25. Eckman MH, Wise R, Leonard AC, et al. Impact of health literacy on outcomes and effectiveness of an educational intervention in patients with chronic diseases. Patient Educ Couns 2012; 87: 143-151.

26. Biadgilign S, Deribew A, Amberbir A, Deribe K. Barriers and facilitators to antiretroviral medication adherence among HIV-infected paediatric patients in Ethiopia: A qualitative study. SAHARA J 2009; 6: 148-154.

27. Lewden C, Drabo YJ, Zannou DM, et al. Disease patterns and causes of death of hospitalized HIV-positive adults in West Africa: a multicountry survey in the antiretroviral treatment era. J Int AIDS Soc 2014; 17: 18797.

28. Fonsah JY, Njamnshi AK, Kouanfack C, et al. Adherence to antiretroviral therapy (ART) in Yaoundé-Cameroon: association with opportunistic infections, depression, ART regimen and side effects. PLoS One 2017; 12: e0170893.

29. Kumar A, Kilaru KR, Sandiford S, Forde S. Trends in the HIV related hospital admissions in the HAART era in Barbados, 2004-2006. AIDS Res Ther 2007; 4: 4. 